\title{
Care of girls and women with Turner syndrome: beyond growth and hormones
}

\author{
Caroline Culen, Diana-Alexandra Ertl, Katharina Schubert, Lisa Bartha-Doering and \\ Gabriele Haeusler
}

University Clinic of Pediatrics and Adolescent Medicine, Medical University of Vienna, Vienna, Austria

Correspondence should be addressed to G Haeusler Email

gabriele.haeusler@ meduniwien.ac.at

\begin{abstract}
Turner syndrome (TS), although considered a rare disease, is the most common sex chromosome abnormality in women, with an incident of 1 in 2500 female births. TS is characterized by distinctive physical features such as short stature, ovarian dysgenesis, an increased risk for heart and renal defects as well as a specific cognitive and psychosocial phenotype. Given the complexity of the condition, patients face manifold difficulties which increase over the lifespan. Furthermore, failures during the transitional phase to adult care result in moderate health outcomes and decreased quality of life. Guidelines on the optimal screening procedures and medical treatment are easy to find. However, recommendations for the treatment of the incriminating psychosocial aspects in TS are scarce. In this work, we first reviewed the literature on the cognitive and psychosocial development of girls with TS compared with normal development, from disclosure to young adulthood, and then introduce a psychosocial approach to counseling and treating patients with TS, including recommendations for age-appropriate psychological diagnostics. With this work, we aim to facilitate the integration of emphasized psychosocial care in state-of-the-art treatment for girls and women with TS.
\end{abstract}

\author{
Key Words \\ - psychosocial care in \\ endocrinology \\ - psychological approach \\ - x-linked \\ - development in Turner \\ syndrome \\ - cognitive profile \\ - psychosocial \\ recommendations in \\ peadiatrics \\ - health autonomy \\ - transition in \\ endocrinological care
}

Endocrine Connections (2017) 6, R39-R51

\section{Introduction}

Turner syndrome (TS) is caused by structural anomalies in or complete loss of the X-chromosome (45X). Although a rare disease with an incidence of 1 in 2500 female births, it is nevertheless the most common sex chromosome abnormality of human females. TS is characterized by short stature and ovarian dysgenesis, together with a broad range of other phenotypic characteristics, including an increased risk for heart and renal defects $(1,2)$.

Clinicians treating girls with TS are challenged with many endocrine, genetic, cardiovascular, developmental, reproductive and psychosocial issues. Medical care of girls with TS in child-centered healthcare systems is therefore highly specialized $(3,4,5,6)$. Reviews of medical care in TS that propose clinical guidelines and recommendations occasionally also mention psychosocial issues $(3,4,7,8)$, but these are no more than footnotes compared with the medical discourse $(9,10)$.

Patients with TS have to cope with many difficulties; they not only need life-long medical surveillance but also psychological care and treatment for a good outcome (6). Symptoms emerge slowly. During the early infancy, affected girls show no psychological developmental differences from their unaffected counterparts. As they grow older their phenotypical, psychosocial and intellectual development is seen to more clearly diverge from that of their normally developing peers. The typical TS-specific cognitive profile is characterized by strengths in verbal skills (11) and relatively weak performance

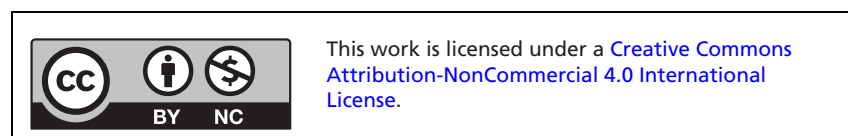


in arithmetic, visuospatial processing and executive functioning (12). In addition, girls with TS have frequently been found to have difficulty in encoding social cues and behaving appropriately in social situations (13). Some cognitive and psychosocial TS phenotypes such as deficits in mathematical abilities (14) and impaired social interaction (13) persist throughout the adult life.

Early diagnosis and treatment of comorbidities is known to enhance the medical state of adult patients with TS (15). Experienced clinicians have discussed inclusion of psychological testing and routinely screening of girls with TS for developmental progress, but evidence-based results are rare (16). Consequently, intervention guidelines for the psychosocial aspects of TS are scarce (13). To our knowledge, no evaluated and documented standardized best practice model is available to provide psychological support for girls and women with TS.

Transition, when adolescents move within the healthcare system from a pediatric protective and authoritative environment to an adult one that demands healthcare autonomy and a degree of independence and responsibility, is a difficult stage. Individual readiness for the process varies and cannot be assumed to be naturally completed by the age of 18 years (17). Previous studies have shown that many young women with TS are 'lost in transition' (18), suggesting that successful passage from pediatric to adult care requires a special focus in TS.

We have developed recommendations towards a psychological and psychosocial approach to improve the care for girls with TS. Our recommendations importantly include supportive interventions encompassing the family system and caregivers. Our overall aim is to empower patients with TS to keep up with their peers at school and in their working life, and to improve their self-esteem and thus their quality of life (QoL). Table 1 gives a summary of the relevant background information, recommendations and psychological tests.

Counseling and treating girls with TS is complicated because although the karyotype differences may affect the phenotype of TS, the karyotype is not a distinct predictor of the physical or psychological phenotypical outcome (19). Consequently, in TS we must acknowledge normal and healthy development while being attuned to the possible impairments.

We thus compare the development in TS with the expected norms of development $(20,21)$ and describe areas of potential impairment as well as possible interventions including psychological screening and testing.
(C) 2017 The authors

http://www.endocrineconnections.org DOI: 10.1530/EC-17-0036

\section{Diagnostic disclosure}

Clinical abnormalities upon which a diagnoses of TS can be made arise from prenatal life until adulthood $(4,22)$. These include suspicious findings of cystic hygroma, increased nucheal translucency in fetal ultrasound, lymphedema on hands and feet and cardiac malformations at birth, short stature during childhood, delayed puberty combined with short stature at adolescence and even premature ovarian failure during adulthood. Ultimately however, $20-30 \%$ of the girls are diagnosed immediately after birth because of phenotype characteristics such as puffy hands, edemas or a webbed neck (7).

Thus, the clinical setting or the practitioners charged with disclosing the TS diagnosis to the parents and/or the patient could be prenatal counseling geneticists, neonatal services, cardiologists, pediatricians, endocrinologists, gynecologists or other specialists. The questions from advice-seeking parents and patients who will require explanation can cover a wide range, from life-deciding aspects of prenatal counseling to short stature and infertility. In all situations, merely explaining that the girl has a chromosomal disorder responsible for a complex combination of multisystem symptoms of unpredictable severity is insufficient to meet many questions raised when a decision is made to investigate the karyotype.

Keeping the TS condition a secret has been shown to have an adverse effect on the patient's well-being, whereas full disclosure to the girl in an empathetic way has been found to support positive integration of the condition (23).

\section{Recommendations}

Given the complexity of a TS diagnosis and treatment, the diagnosis needs to be clearly communicated to the parents from the beginning, and to the child having regard to her age and developmental stage. The earlier the diagnosis is communicated, the better is the outcome for the girl's future QoL and self-esteem (23). Furthermore, honesty about the condition within the family is essential. Pediatricians should offer assistance to overstrained parents in disclosing the condition to their daughters in an age-appropriate manner. Providing written information on the most important issues of TS to facilitate digesting the diagnosis over a period of time might be worthy of consideration (23). The clinician charged with disclosing the diagnosis should be familiar with all aspects of TS. He or she should set aside sufficient time to inform the 
Table 1 Background information, recommendations and psychological tests.

\begin{tabular}{|c|c|}
\hline & Normative developmental co \\
\hline Age & $\begin{array}{c}\text { Developmental tasks } \\
\text { (Robert J Havighurst (20)) }\end{array}$ \\
\hline \multicolumn{2}{|l|}{$\begin{array}{l}\text { Diagnosis } \\
\text { disclosure }\end{array}$} \\
\hline Infancy $0-5$ & $\begin{array}{l}\text { - } \text { Caregiver-child-detachment } \\
\text { - Regulation of physiological } \\
\text { processes, primary needs, take } \\
\text { solid food } \\
\text { - Language abilities } \\
\text { - } \text { Motor skills: crawl, walk-control } \\
\text { elimination of body wastes - } \\
\text { development of basic autonomy } \\
\text { - Describing social and physical } \\
\text { reality } \\
\text { - Forming concepts, playing }\end{array}$ \\
\hline $\begin{array}{l}\text { Childhood } \\
6-12\end{array}$ & $\begin{array}{l}\text { - Getting along with age mates } \\
\text { - Physical skills necessary for } \\
\text { ordinary games } \\
\text { - Developing concepts necessary } \\
\text { for everyday living } \\
\text { - Developing conscience, morality } \\
\text { and a sale of values } \\
\text { - Masculine or feminine role } \\
\text { - Developing attitudes toward } \\
\text { social groups/institutions } \\
\text { - Achieving personal } \\
\text { independence }\end{array}$ \\
\hline
\end{tabular}

Playing, pretending, no logic thinking, but forming concepts, no manipulation of information mentally, egocentric stage

Ability to think logically, when concrete subjects involved, classification skills improve, egocentric view is over, viewpoints of others can be taken in account independence

\footnotetext{
Adolescence - Achieving a masculine or feminine social role

- Accepting one's physique and using the body effectively

- Achieving new and more mature relations with age mates of both sex

- Achieving emotional independence of parents and other adults

- Desiring and achieving socially responsible behavior
}

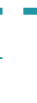

\section{Turner syndrome: pullouts for} psychosocial care

- Clear and empathic communication, in depth knowledge on the condition is required

- Sufficient time to answer questions

- Within the family: emphasizing being honest about diagnosis, full disclosure to the girl

- Thorough documentation about information provided

- Information about self-help groups,

literature, etc.

- Diagnosis disclosure is an ongoing process along the way of the girl's development

- Development in infancy seems to be inconspicuous

- Growth deficit becomes obvious, use TS-specific growth charts

Clinician should be aware of:

- Specific cognitive phenotype and psychosocial phenotype in TS

- Higher risk for ADHD, autistic traits

If developmental deficits are suspected:

- Screening for motor skills

- Screening for neurodevelopmental deficits

- Ask for achievements in school - when difficulties are reported, organize specific support

- Specific risk of impairment in visual memory, visual attention, visuospatial processing. organize specific support

- Explore social behavior and social activities

- when difficulties are reported: give recommendation for social skill training

Girls with TS identify as female, puberty matters require diligent discussion and empathy

- Start to explain normal pubertal development around age 10 years

- Explain the need to induce puberty, if laboratory results point to ovarian failure around age 11 years

Thinking logically and abstract, able to use metacognition, problem solving in multiple steps develops

Psychosocial issues increase during adolescence, self-perception may be affected in a negative way:

- Romantic love, sexuality and fertility matters should be addressed

- Involve a specialized endocrine gynecologist for information on estrogen substitution, fertility matters

Cognition: verbal skills are in normal range, but impairments in executive functioning, self-regulation, working memory, planning skills and abstract reasoning might emerge

- Organize psychological testing and support (complex cognitive processes), if necessary

Vocational planning should start

- Support emancipating from parents, encourage health autonomy and self-care skills in an age-appropriate way (Lit Tabell zitieren)
Psychological tools

Bailey scales, WIPPSI-III,

NEPSY, KABC-II, SSIS, CBCL

WISC, NEPSY,

KABC-II, SSIS, CBCL, YSR, TRF

WISC, WAIS

NEPSY, KABC-II, SSIS, CBCL, YSR, TRF, TRAQ 
Table 1 Continued.

\begin{tabular}{|c|c|c|}
\hline \multicolumn{3}{|c|}{ Normative developmental concepts } \\
\hline Age & $\begin{array}{c}\text { Developmental tasks } \\
\text { (Robert J Havighurst (20)) }\end{array}$ & $\begin{array}{c}\text { Cognition } \\
\text { (Jean Piaget (21)) }\end{array}$ \\
\hline \multicolumn{3}{|l|}{ Transition } \\
\hline $\begin{array}{l}\text { Young } \\
\text { adulthood } \\
18+\end{array}$ & $\begin{array}{l}\text { - Selecting a mate, learning to } \\
\text { live with a partner } \\
\text { - Starting family, rearing children } \\
\text { - Getting started in occupation } \\
\text { - Taking on civic responsibility } \\
\text { - Finding a congenial social group }\end{array}$ & \\
\hline
\end{tabular}

\begin{tabular}{|c|c|}
\hline $\begin{array}{c}\text { Turner syndrome: pullouts for } \\
\text { psychosocial care }\end{array}$ & $\begin{array}{c}\text { Psychological } \\
\text { tools }\end{array}$ \\
\hline $\begin{array}{l}\text { - Follow the process of transition readiness, } \\
\text { use questionnaires enquiring healthcare } \\
\text { autonomy, self-care, disease management }\end{array}$ & TRAQ \\
\hline $\begin{array}{l}\text { Transition matters: concrete phase of starting } \\
\text { to transition, contacting adult providers } \\
\text { - Address sexuality and fertility matters } \\
\text { Given social impairments in TS } \\
\text { - Supporting young women and their families } \\
\text { for living as independently as possible } \\
\text { - Enhancing academic career, job training, } \\
\text { professional life } \\
\text { - Promoting hobbies, voluntary work, creative } \\
\text { abilities, etc. can counteract social isolation } \\
\text { and dependency on family }\end{array}$ & $\begin{array}{l}\text { WAiS, KABC-II, } \\
\text { SSIS, CBCL, YSR }\end{array}$ \\
\hline
\end{tabular}

should be initiated at an early stage and remain an integral part of the patient's routine treatment.

Furthermore, information about self-help groups, support groups and specialist literature may be helpful.

\section{Infancy, 0-2 years}

A divergence from normal psychosocial development is unobservable during infancy in girls with TS (30). However, height and weight typically drops below that of age-matched normal developing girls (31), often causing parental concern. Mothers especially worry about a child's failure to gain weight $(32,33,34,35)$ as weight gain is closely related to maternal responsibilities and abilities. Furthermore, even where there is no obvious aberration parents are anxious to receive advice on how best to nurture the child.

\section{Recommendations}

In the case of an antenatal or postpartum diagnosis of TS, a positive child-mother/father attachment is crucial and will be enhanced by diligent disclosure (see above). TS-specific growth charts (36) are useful for monitoring expected growth and weight gain and relieve mothers of guilt feelings.

Additionally, pediatricians should be attuned to sleeping and eating habits or emotional disturbances of the infant because irregularities stress the mother-child dyad and mothers might need support in adjusting to their baby's demands (37). Screening by using the Bayley scale (38) is strongly recommended as soon as delayed development is suspected.

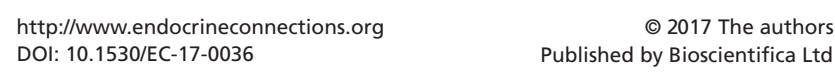




\section{Early childhood, 2-6 years}

The difference in height compared with age-mates becomes obvious in early childhood. However, there is no evidence of any difference in development between girls with TS and their age mates regarding basic achievements such as controlling body functions, playing and operating with simple cognitive concepts. Albeit, reduced attention spans and a preference for playing with younger children have been observed in girls with TS, which might be due to the specific cognitive phenotype in TS (described in detail in the paragraph childhood, age 6-12 years) that is more obvious at a later age and includes attention deficits, hyperactivity and poorer social competence $(12,39,40)$.

\section{Recommendations}

If short stature of a girl with TS is reported to become an issue within the family, both the psychosocial and auxological aspects should be considered. The benefit of an early start of GH therapy for catch-up-growth aimed at the lower normal range or even normal range (16) should be weighed against the possible strain from daily injections. As there are no data about a benefit from an early start on final height, the authors are reluctant to start GH therapy before the age of 4 years in their clinic.

Given the evidence of a specific cognitive and psychosocial phenotype in TS, pediatricians should be attuned to upcoming developmental impairments and therefore explore the child's social behavior, playing habits, concentration levels, cognition and communication skills.

When peculiarities are reported, psychological counseling and/or screening by using the Bayley scale for development in general, Wechsler Preschool and Primary Scale of Intelligence (WIPPSI) (41) for cognitive development or A Developmental NEuroPSYchological Assessment (NEPSY-II) (42, 43) for assessing neuropsychological domains and the Social Skills Improvement System Rating Scale (SSIS) (44) respectively the Child Behavior Checklist (CBCL) $(45,46)$ for social behavioral assessment are recommended. Figures 1 and 2 give brief information on the psychological tests recommended.

Occupational therapy $(47,48)$ may be helpful when delays or disorders in the psychosocial development of a girl become apparent at this early age. Occupational therapists should give training to patients with TS to improve their sensory processing, promote functional and coping skills as well as advising and encouraging parents to adopt beneficial strategies.

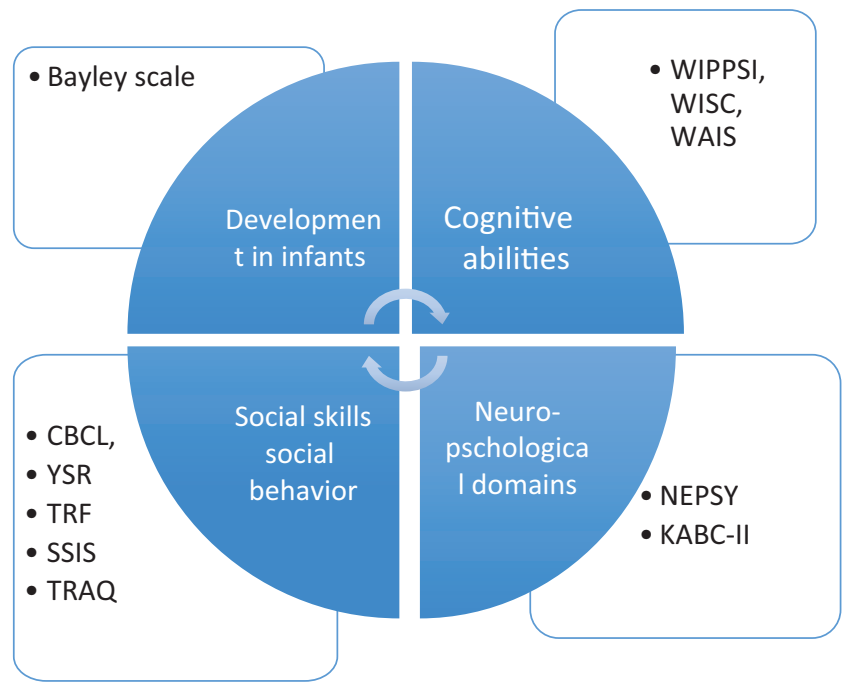

Figure 1

Psychological tests matched with areas of interest.

\section{Childhood, 6-12 years}

Physically, girls with TS grow slower and attain shorter height than their normally developing counterparts $(4,7)$, provoking comments from age mates and adults. Parents and children perceive the child's QoL, taking height into account, differently, parents rating it lower than the young girls do (49).

Studies describe TS-related impairment of motor abilities including fine motor skills, endurance in physical activities and body balance (50).

Most girls with TS show a normal Full Scale Intelligence Quotient (FSIQ) with no prevalence of mental or massive cognitive impairment. Mental retardation is observed only in approximately $10 \%$ of the girls, mostly those with a ring or marker chromosome (7). However, TS generally is associated with a specific cognitive phenotype with a consistent shift towards a higher Verbal Intelligence Quotient (VIQ) and a lower Performance Intelligence Quotient (PIQ) $(11,51)$. The girls' mathematical abilities are commonly impaired $(14,52)$. Furthermore, deficits in visuospatial processing, visual memory and visual attention become obvious between the ages of 6 and 12 years $(12,13,53,54,55)$. Girls with TS are also at a higher risk for neurodevelopmental conditions such as attention-deficit hyperactivity disorder $(56,57,58)$. These setbacks lead to problems at school (51). A total of $40-70 \%$ of the girls have been reported as having learning difficulties $(7,59)$.

Psychosocial problems also become obvious at this age. Poorer social skills have consistently been described as affecting all aspects of social behavior and functioning

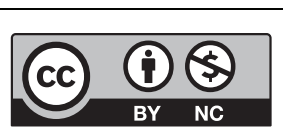

This work is licensed under a Creative Commons Attribution-NonCommercial 4.0 International License. 


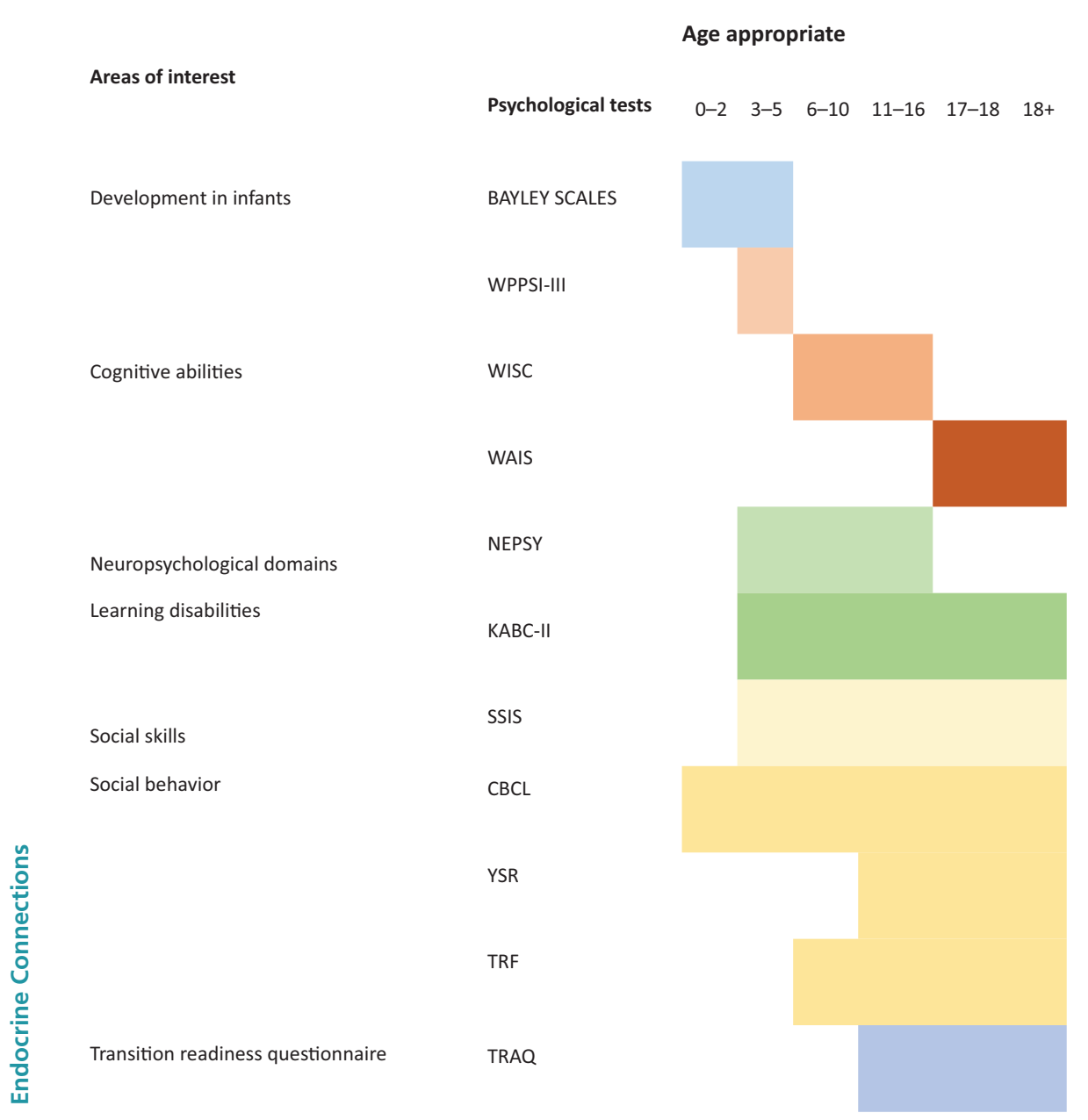

Figure 2

Overview of age-appropriate testing.
$(13,56,60)$. The girls tend to have fewer close friends, spend less time with peers and appear emotionally less mature than age-matched normally developing girls. Building up friendships and maintaining relationships are difficult for them and parents report that their daughters with TS as less socially competent than their peers (13).

\section{Recommendations}

Reactions and comments from the social environment relating to the child's shorter height should be discussed between pediatricians and the parents as well as the child in an age-appropriate way to best cope with the child's increasing perception of being of a different height. This is the very latest point at which specialists in growth disorders should be involved to ensure parents receive state-of-theart recommendations based on the latest findings in $\mathrm{GH}$ therapy also taking QoL outcomes into account.

Considering possible motor deficits also in adult age (61), we recommend encouraging girls with TS to undertake physical activities such as dancing, walking, swimming, hiking, biking, etc. and train their motor skills. Always bear in mind the special health condition of TS and ensure recommendations are in line with the girl's specific situation.

School progress is of major concern for parents and may greatly affect the girls' future QoL. Exploring school matters and recommending evaluation when difficulties with school subjects and/or concentration are reported is essential. Assessment using the WISC (62), the NEPSY $(42,43)$ or the Kaufman Assessment Battery for Children (KABC-II) (63) (Figs 1 and 2) is decisive for tailored cognitive remediation.

Furthermore, the way a girl interacts with peers provides information about age-appropriate social development. Screening for social behavior impairments by using the SSIS, CBCL or the Teacher Report Form (TRF) $(45,64)$ helps to explore these topics. Social skills intervention groups might help the patient if she has problems getting along with peers or is socially isolated.

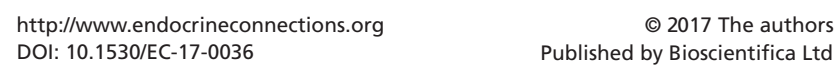




\section{Adolescence, 13-18 years}

Delayed puberty or the absence of pubertal development is the main medical and psychosocial issue during the phase of adolescent age and will lead to intensified medical care $(3,4)$. Additionally, during adolescence girls with TS increasingly fall behind in normal cognitive development. Tasks such as abstract reasoning, clustering and the use of metacognition are likely to become a challenge. Difficulties in mastering social cognitive tasks are especially evident when multiple cognitive domains are required (65). These findings correlate with deficits reported in other areas of cognition where executive functioning is involved $(40,66,67)$. Limitations in working memory and slower response times indicate deficits in executive functioning that commonly result in weak planning, self-organization and self-regulation performances $(12,13,39,40,53,66,68)$.

Verbal skills, however, are relatively strong in girls with TS, with normal to above average scores generally reported (11). Recent studies indicate a possible specific TS profile in language use abilities with increased vocabulary, initial verbal memory, reading comprehension and understanding of rarely used words. Sometimes reported slow responding and weak performances in verbal fluency tasks are less related to linguistic skills but rather reflect underlying deficits in executive functioning $(69,70,71)$.

Adolescent girls with TS tend to have more difficulties than their age-matched peers to emancipate from their families, which might be due to increased anxiety, hyperactivity, impulsivity (72) or traits seen on the autism spectrum $(55,73,74,75)$. However, girls with TS differ in an important respect from patients with autism: they do desire social interaction (60).

Romantic love and sexual relationships are yet another sensitive topic emerging at this age $(29,56)$. Young girls with TS experience primary amenorrhea and impaired psychosexual development despite their female gender identification. Often, their first sexual experiences are delayed and subsequent experiences infrequent (76). Moreover, limited sexual experience is associated with lower self-esteem $(29,77)$.

\section{Recommendations}

The need for estrogen substitution to promote feminization is the central topic in the pediatric-endocrine setting at the end of the childhood stage or at the latest during early adolescence. Full information about the biological background of ovarian insufficiency in TS should be given again to the parents and in an age-appropriate manner to the girl.

Progress in education and vocational planning are decisive for the girls' future QoL as we will explicate below. Intensive exploration of cognitive and psychosocial development is essential. Reports of weak academic achievements and/or social problems are indications for psychological counseling or assessment. The psychological tests (WISC, NEPSY, KABC-II, SSIS, CBCL, YSR, TRF) we recommend are listed in Figs 1 and 2. Early intervention in school matters such as contacting and involving supportive teachers may be of great help.

We propose group training for social cognition and competence, where social skills are lacking.

Equally important are questions concerning romantic feelings, sexuality and fertility. As parents often have difficulties broaching these sensitive topics, healthcare professionals need to address them and provide in-depth information.

We recommend that special attention is given and extra resources are mustered to manage the sensitive phase of transition, see 'Health autonomy and transition' below.

\section{Health autonomy and transition}

Many difficulties and poor medical care of adult women with TS during the transition process have been reported $(18,78)$. Effective coordination and continuity of healthcare during a chronically ill adolescent's transition to adult care is critical for the patient's medical and emotional state in adulthood $(17,79,80)$. The chances for a successful transition are decreased in some chronic conditions, including TS, because it is difficult to find experts in adult care (81). Young women with TS are furthermore seldom fully aware of their conditions $(82,83)$. In adult life, less than $4 \%$ of patients with TS undergo all the recommended medical investigations on a regular basis (84).

There are many reasons for transition failures such as poor self-advocacy or self-management, little family support or unsatisfactory cooperation between healthcare professionals and organizational structures (85). Self-care and healthcare autonomy, both considered preconditions for a successful transition, involve complex cognitive and regulatory dimensions $(86,87)$. Unfortunately, planning and self-organizational skills in girls with TS may be impaired even more than in other chronic conditions. Taking over responsibilities additionally to emancipation 
from their parents is likely to be a major hurdle for them. Therefore, extra effort and proactive action are required from healthcare professionals at this stage of development $(81,88)$.

Experts agree that a good QoL is the most important outcome. Building up a relationship of trust with new healthcare professionals, and having a social network are essential for a successful transition. Patients' understanding of their condition, its possible complications and medication as well as adherence to medication regimens and self-management are also seen as important individual contributors to achieve a good QoL (89).

Numerous transition programs have been introduced for a wide range of chronic diseases (90, 91, 92, 93, 94, 95) but, despite concerted efforts, results are still disappointing and transition in general is associated with poor health outcomes, non-adherence and no-shows at potential healthcare providers' appointments $(96,97)$.

\section{Recommendations}

Various transition models have been developed for chronically ill patients $(98,99)$. These commonly recommend informing the patients early (11-13 years) about health issues (27). Especially in complex diagnoses such as TS and where diagnostic disclosure may have taken place more than 10 years earlier, updating information on medical and health issues given to the parents and increasingly conversing with the patient alone is of crucial importance (27).

In addition, awareness of the process of 'transition readiness' has been recommended (100). In this process of transition, the developmental age is more important than the chronological age $(4,101)$, which is probably even truer for girls with TS, given their potential complex psychosocial impairments. Professionals should cooperate with parents in enabling adolescents to become more independent (102).

We recommend clinicians adopt the process of transition readiness. To our knowledge, no TS-specific transition readiness process has been developed. However, a disease-neutral questionnaire could serve this purpose. We recommend the Transition Readiness Assessment Questionnaire (TRAQ) (103) because of its economic features, clear structure and ease of use. It helps in deciding if the girl is ready for transition or whether education on health issues and an increase in healthcare autonomy is still needed.
Inclusion of a specialized gynecologist from the age of 16 years onwards is important to provide the women with information about current best practice in estrogen substitution and in-vitro fertilization. Once health autonomy has been gained and medical follow-up has been personalized, the young women will be dismissed from pediatric care. We recommend a tertiary center for the care after the patients' childhood and adolescence.

\section{Adulthood}

Adult women with TS not only face a decreased health status but also manifold psychosocial difficulties. Being unable to give birth and raise biological children causes grief in patients with TS. Although fertility aid is changing rapidly as research and possibilities in reproductive medicine develop $(104,105)$, still, the only slight chance of getting pregnant spontaneously and the health risk in pregnancy is of great concern for women with TS (106).

Height and the estimated benefit from GH therapy have been found to have no influence on QoL $(107,108$, 109). Although overall QoL results have been normal in women with TS aged approximately 20-25 years, results of studies in women over 35 years of age are inconsistent (reviewed in (109)).

Women with TS show higher levels of alexithymia (110) and score lower in tests on self-perception and attitude towards their body than normally developing girls, even after they achieve a height in the lower normal range with growth hormone therapy (111). This negative self-perception might be the result of them being aware of atypical physical development in adolescence and perceiving the absence of spontaneous pubertal development (4).

A sexual relationship is known to help protect against feelings of loneliness or negative self-perception (28). Unfortunately, however, fewer women with TS than their age-matched peers report living in a sexual active partnership and in addition single women with TS report low sexual activities (112).

Adult women with TS tend to leave the family home later in life (113). More women with TS than age-matched control women remain unmarried and they report fewer social contacts (114). Lower psychosocial well-being seems to correlate with sex hormone deficiency but also with reported learning difficulties at school in the past (113).

The literature is contradictory on QoL associated with vocational training and employment. Less employment or 
employment below the women's vocational training lead to lower overall life satisfaction correlated to professional life than in control women (115). In contrast, some studies have reported educational achievements and job levels in women with TS equal (76) or even above that of the average female population in the United States (116).

\section{Recommendations}

Our proposed model of care during adulthood is for close collaboration between an endocrine gynecologist, cardiologist and internist with internal medicine becoming more and more important with increasing age.

Regarding family planning and raising children, information about various options should be given at the time of actual need and involve an informed team familiar with the options and risks of induced pregnancy after oozyte donation. Adoption should be considered as another way of fulfilling motherhood desires $(117,118)$.

Our task as healthcare providers must be to ensure young women with TS are well equipped to deal with the future challenges of their professional and social life. This includes instilling the importance of training for an appropriate career and considering integration into a social group outside their family of origin or romantic relationships. Importantly, the interests and particular qualities of women with TS such as creative abilities, enjoying voluntary work, activities close to nature, working with children, traveling etc. ought to be emphasized.

\section{Psychological tests}

As economic resources are usually limited, we have compiled a list of the most important physiological tests we would recommend that are also specifically reported in the literature on TS. These tests in our view identify cognitive, emotional and social deficits in a relatively short time with a low personnel cost.

Psychological tests we recommend:

- The Bayley Scales assess developmental levels of infants in the domains of motor skills, cognition, language, social-emotional and adaptive behavior (38).

- The Wechsler Preschool and Primary Scale of Intelligence (WIPPSI), the Wechsler Intelligence Scale for Children (WISC) and the Wechsler Adult Intelligence Scale (WAIS) assess verbal and non-verbal abilities $(41,119)$.

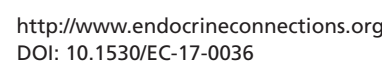

- The Developmental NEuroPSYchological Assessment (NEPSY-II) examines neuropsychological domains including social cognition and is useful in planning intervention for various childhood disorders (42).

- The Social Skills Improvement System Rating Scale (SSIS) locates social skills, competing behavior problems and academic competence (44).

- The Kaufman Assessment Battery for Children (KABC-II) identifies learning disabilities or developmental problems (63).

- The various forms of the Achenbach System of Empirically Based Assessment $(45,46)$ pinpoint problems such as depressive symptoms, anxiety or attention deficits in children and adolescents.

- The Child Behavior Checklist (CBCL) is a caregiver report form, whereas the Youth Self Report Form (YSR) is filled out by children and adolescents. The Teacher Report Form (TRF) may be of additional use for providing information in school matters.

More detailed recommendations on developmental tests are provided in the literature by Weitzman and coworkers (120) and the Council on Children with Disabilities (121).

\section{Conclusion for the psychosocial care of girls with TS}

Given the complexity of a TS diagnosis and the psychosocial impact of the condition, counseling on psychosocial issues and addressing concerns about the girls' daily life and future adult life needs to be integrated into standard pediatric endocrinologist care. Importantly, counseling should always be one step ahead. Accordingly, our recommendations mostly deal with potential upcoming or expected difficulties in growing up with TS. They aim to enhance pediatricians' preparedness while incorporating support from psychologists or other healthcare providers for optimal treatment of girls with TS.

Centers that treat girls and young women with TS are challenged to develop a supportive mode of transition to increase the chances for patients with TS to receive the best medical care and psychosocial support throughout their adulthood. Health autonomy is of central importance for women with TS as tertiary centers for rare diseases are imminently to be established for diagnosis made during childhood.

We contend that a multidisciplinary standard of care based on well-defined screening would greatly improve

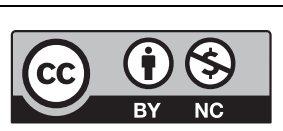

This work is licensed under a Creative Commons Attribution-NonCommercial 4.0 International License. 
the long-term outcomes of patients with TS. Until such a standard is universally established, we are convinced that if account is taken of the considerations we have set out; even practitioners acting on a lower economic level will be able to improve the long-term outcomes for patients with TS.

\section{Declaration of interest}

The authors declare that there is no conflict of interest that could be perceived as prejudicing the impartiality of this review.

\section{Funding}

This paper was supported by an 'investigator initiated grant' from Pfizer.

\section{References}

1 Ford CE, Jones KW, Polani PE, De Almeida JC \& Briggs JH. A sex-chromosome anomaly in a case of gonadal dysgenesis (Turner's syndrome). Lancet 19591 711-713. (doi:10.1016/S01406736(59)91893-8)

2 Hall JG \& Gilchrist DM. Turner syndrome and its variants. Pediatric Clinics of North America 199037 1421-1440. (doi:10.1016/S0031-3955(16)37018-3)

3 Saenger P, Wikland KA, Conway GS, Davenport M, Gravholt CH, Hintz R, Gravholt CH, Hintz R, Hovatta O, Hultcrantz M, et al. Recommendations for the diagnosis and management of Turner syndrome. Journal of Clinical Endocrinology and Metabolism 200186 3061-3069. (doi:10.1210/jc.86.7.3061)

4 Bondy CA. Care of girls and women with turner syndrome: a guideline of the turner syndrome study group. Journal of Clinical Endocrinology and Metabolism 200792 10-25. (doi:10.1210/ jc.2006-1374)

5 Pinsker JE. Turner Syndrome: updating the paradigm of clinical care. Journal of Clinical Endocrinology and Metabolism 201297 E994-E1003. (doi:10.1210/jc.2012-1245)

6 Backeljauw PF, Bondy C, Chernausek SD, Cernich JT, Cole DA, Fasciano LP, Foodim J, Hawley S, Hong DS, Knickmeyer RC, et al. Proceedings from the turner resource network symposium: the crossroads of health care research and health care delivery. American Journal of Medical Genetics Part A 2015 167A 1962-1971.

7 Sybert VP \& McCauley E. Turner's syndrome. New England Journal of Medicine 2004351 1227-1238. (doi:10.1056/NEJMra030360)

8 Donaldson MDC. Optimising management in Turner syndrome: from infancy to adult transfer. Archives of Disease in Childhood 200691 513-520. (doi:10.1136/adc.2003.035907)

9 Mortensen KH, Cleemann L, Hjerrild BE, Nexo E, Locht $\mathrm{H}$, Jeppesen EM \& Gravholt $\mathrm{CH}$. Increased prevalence of autoimmunity in Turner syndrome - influence of age. Clinical and Experimental Immunology 2009156 205-210. (doi:10.1111/j.13652249.2009.03895.x)

10 Mortensen KH, Andersen NH \& Gravholt CH. Cardiovascular phenotype in turner syndrome-integrating cardiology, genetics, and endocrinology. Endocrine Reviews 201233 677-714. (doi:10.1210/er.2011-1059)

11 Temple CM. Oral fluency and narrative production in children with Turner's syndrome. Neuropsychologia 200240 1419-1427. (doi:10.1016/S0028-3932(01)00201-9)

12 Hong D, Scaletta Kent J \& Kesler S. Cognitive profile of turner syndrome. Developmental Disabilities Research Reviews 200915 270-278. (doi:10.1002/ddrr.79)
13 Lepage J-F, Dunkin B, Hong DS \& Reiss AL. Impact of cognitive profile on social functioning in prepubescent females with Turner syndrome. Child Neuropsychology 201319 161-172. (doi:10.1080/ 09297049.2011.647900)

14 Baker JM \& Reiss AL. A meta-analysis of math performance in Turner syndrome. Developmental Medicine and Child Neurology 201658 123-130. (doi:10.1111/dmcn.12961)

15 Sakakibara H, Yoshida H, Takei M, Katsuhata Y, Koyama M, Nagata T, Ishikawa M \& Hirahara F. Health management of adults with Turner Syndrome: an attempt at multidisciplinary medical care by gynecologists in cooperation with specialists from other fields: health management of Turner Syndrome adults. Journal of Obstetrics and Gynaecology Research 201137 836-842. (doi:10.1111/j.1447-0756.2010.01448.x)

16 Davenport ML. Approach to the patient with Turner syndrome. Journal of Clinical Endocrinology and Metabolism 201095 14871495. (doi:10.1210/jc.2009-0926)

17 Rosen DS, Blum RW, Britto M, Sawyer SM \& Siegel DM. Transition to adult health care for adolescents and young adults with chronic conditions. Journal of Adolescent Health 200333 309-311. (doi:10.1016/S1054-139X(03)00208-8)

18 Davies M. Lost in transition: the needs of adolescents with Turner syndrome: needs of adolescents with Turner syndrome. BJOG 2010117 134-136. (doi:10.1111/j.14710528.2009.02410.x)

19 Al Alwan I, Khadora M, Amir I, Nasrat G, Omair A, Brown L, Al Dubayee $M \&$ Badri M. Turner syndrome genotype and phenotype and their effect on presenting features and timing of diagnosis. International Journal of Health Sciences 20148195. (doi:10.12816/0006086)

20 Havighurst RJ. Developmental Tasks and Education. London, UK: Longman Group, 1972.

21 Adult RL. Children's Cognitive Development: Piaget's Theory and the Process. New York, NY, USA: Oxford Univ. Press, 1977.

22 Stochholm K, Juul S, Juel K, Naeraa RW \& Gravholt CH. Prevalence, incidence, diagnostic delay, and mortality in Turner syndrome. Journal of Clinical Endocrinology and Metabolism 2006 91 3897-3902. (doi:10.1210/jc.2006-0558)

23 Sutton EJ, Young J, McInerney-Leo A, Bondy CA, Gollust SE \& Biesecker BB. Truth-telling and turner syndrome: the importance of diagnostic disclosure. Journal of Pediatrics 2006148 102-107. (doi:10.1016/j.jpeds.2005.08.022)

24 Mangset M \& Hofmann B. LQTS parents' reflections about genetic risk knowledge and their need to know or not to know their children's carrier status. Journal of Genetic Counseling 201423 1022-1033. (doi:10.1007/s10897-014-9727-2)

25 Stephure DK \& Canadian Growth Hormone Advisory Committee. Impact of growth hormone supplementation on adult height in turner syndrome: results of the Canadian randomized controlled trial. Journal of Clinical Endocrinology and Metabolism 200590 3360-3366. (doi:10.1210/jc.2004-2187)

26 Saenger P. Transition in Turner's syndrome. Growth Hormone and IGF Research 200414 S72-S76. (doi:10.1016/j.ghir.2004.03.017)

27 Lemly DC, Weitzman ER \& O'Hare K. Advancing healthcare transitions in the medical home: tools for providers, families and adolescents with special healthcare needs. Current Opinion in Pediatrics 201325 439-446. (doi:10.1097/ MOP.0b013e3283623d2f)

28 Dołęga Z, Jeż W \& Irzyniec T. Efekt kohorty w badaniach różnic w funkcjonowaniu psychospołecznym kobiet z zespołem Turnera. Endokrynologia Polska 201465 287-294. (doi:10.5603/ ep.2014.0039)

29 Carel J-C, Elie C, Ecosse E, Tauber M, Léger J, Cabrol S, Nicolino M, Brauner R, Chaussain JL \& Coste J. Self-esteem and social adjustment in young women with turner syndrome-influence of pubertal management and sexuality: population-based cohort 
study. Journal of Clinical Endocrinology and Metabolism 200691 2972-2979. (doi:10.1210/jc.2005-2652)

30 Gonzalez L \& Witchel SF. The patient with Turner syndrome: puberty and medical management concerns. Fertility and Sterility 201298 780-786. (doi:10.1016/j.fertnstert.2012.07.1104)

31 Häusler G, Frisch H, Schober E \& Waldhauser F. Age-related changes in stimulation and secretory rhythm of serum gonadotropins in children with Ullrich-Turner syndrome. Monatsschrift Kinderheilkd Organ Dtsch Ges Für Kinderheilkd 1988 136 152-155.

32 Sullivan PB, Lambert B, Rose M, Ford-Adams M, Johnson A \& Griffiths P. Prevalence and severity of feeding and nutritional problems in children with neurological impairment: Oxford Feeding Study. Developmental Medicine and Child Neurology 2000 42 674-680. (doi:10.1017/S0012162200001249)

33 Hollén LI, Din Z, Jones LR, Emond AM \& Emmett P. Are diet and feeding behaviours associated with the onset of and recovery from slow weight gain in early infancy? British Journal of Nutrition 2014111 1696-1704.

34 Fildes A, van Jaarsveld CHM, Llewellyn C, Wardle J \& Fisher A. Parental control over feeding in infancy. Influence of infant weight, appetite and feeding method. Appetite 201591 101-106. (doi:10.1016/j.appet.2015.04.004)

35 Fildes A, van Jaarsveld CHM, Llewellyn C, Wardle J \& Fisher A. Prevalence and severity of feeding and nutritional problems in children with neurological impairment: Oxford Feeding Study. Appetite 201591 101-106. (doi:10.1016/j.appet.2015.04.004)

36 Haeusler G, Schemper M, Frisch H, Blümel P, Schmitt K \& Plöchl E. Spontaneous growth in Turner syndrome: evidence for a minor pubertal growth spurt. European Journal of Pediatrics 1992151 283-287. (doi:10.1007/BF02072230)

37 Dale LP, O'Hara EA, Keen J \& Porges SW. Infant regulatory disorders: temperamental, physiological, and behavioral features. Journal of Developmental and Behavioral Pediatrics 201132 216-224. (doi:10.1097/DBP.0b013e3181e32c4f)

38 Reuner G \& Rosenkranz J. Bayley-Scales of Infant and Toddler Development, Third Edition. German version. Frankfurt, Germany: Pearson Assessment, 2014.

39 Ross JL, Roeltgen D, Kushner H, Wei F \& Zinn AR. The Turner syndrome-associated neurocognitive phenotype maps to distal Xp. American Journal of Human Genetics 200067 672-681. (doi:10.1086/303039)

40 Ross J, Roeltgen D \& Zinn A. Cognition and the sex chromosomes: studies in turner syndrome. Hormone Research 2006 65 47-56. (doi:10.1159/000090698)

41 Wechsler D. Wechsler Preschool and Primary Scale of Intelligence - III. German version. Frankfurt, Germany; Pearson Assessment, 2009.

42 Korkman M, Kirk U \& Kemp SL. NEPSY II. Administrative manual. San Antonio, TX, USA: PsychCorp, Pearson, 2007.

43 Brooks BL, Sherman EMS \& Strauss E. NEPSY-II: a developmental neuropsychological assessment, second edition. Child Neuropsychology 200916 80-101. (doi:10.1080/09297040903146966)

44 Gresham F \& Elliott SN. Social Skills Improvement System (SSIS) Rating Scales. San Antonio, TX, USA: PsychCorp, Pearson, 2008.

45 Achenbach TM \& Rescorla L. Practical applications of the achenbach system of empirically based assessment (ASEBA) for ages 1.5 to $90+$ years. In 2004-The International Test Users' Conference. Camberwell, Australia: Australian Council for Educational Research, 2004. (available at: http://research.acer. edu.au/cgi/viewcontent.cgi?article=1007\&context=research conferenceITU_2004)

46 Achenbach T. The Achenbach System of Empirically Based Assessment (ASEBA). Burlington, VT, USA: ASEBA. (available at: http://www.aseba.org/)
47 Blanche EI, Chang MC, Gutiérrez J \& Gunter JS. Effectiveness of a sensory-enriched early intervention group program for children with developmental disabilities. American Journal of Occupational Therapy 201670 7005220010p1-7005220010p8. (doi:10.5014/ ajot.2016.018481)

48 Fabrizi SE, Ito MA \& Winston K. Effect of occupational therapyled playgroups in early intervention on child playfulness and caregiver responsiveness: a repeated-measures design. American Journal of Occupational Therapy 201670700220020 p1700220020p9. (doi:10.5014/ajot.2016.017012)

49 Otero SC, Eiser C, Wright NP \& Butler G. Implications of parent and child quality of life assessments for decisions about growth hormone treatment in eligible children: quality of life assessments for growth hormone treatment. Child: Care, Health and Development 201339 782-788.

50 Milde K, Tomaszewski P \& Stupnicki R. Physical fitness of schoolgirls with Turner syndrome. Pediatric Exercise Science 2013 25 27-42. (doi:10.1123/pes.25.1.27)

51 Mazzocco MMM. The cognitive phenotype of Turner syndrome: specific learning disabilities. International Congress Series 2006 1298 83-92. (doi:10.1016/j.ics.2006.06.016)

52 Kesler SR. Neurofunctional differences associated with arithmetic processing in turner syndrome. Cerebral Cortex 200516 849-856. (doi:10.1093/cercor/bhj028)

53 Kirk JW, Mazzocco MM \& Kover ST. Assessing executive dysfunction in girls with fragile $\mathrm{X}$ or Turner syndrome using the Contingency Naming Test (CNT). Developmental Neuropsychology 200528 755-777. (doi:10.1207/s15326942dn2803_2)

54 Beaton EA, Stoddard J, Lai S, Lackey J, Shi J, Ross JL \& Simon TJ. Atypical functional brain activation during a multiple object tracking task in girls with turner syndrome: neurocorrelates of reduced spatiotemporal resolution. American Journal on Intellectual and Developmental Disabilities 2010115 140-156. (doi:10.1352/1944-7558-115.2.140)

55 Knickmeyer RC \& Davenport M. Turner syndrome and sexual differentiation of the brain: implications for understanding male-biased neurodevelopmental disorders. Journal of Neurodevelopmental Disorders 20113 293-306. (doi:10.1007/ s11689-011-9089-0)

56 McCauley E, Feuillan P, Kushner H \& Ross JL. Psychosocial development in adolescents with Turner syndrome. Journal of Developmental and Behavioral Pediatrics 200122 360-365. (doi:10.1097/00004703-200112000-00003)

57 Green T, Chromik LC, Mazaika PK, Fierro K, Raman MM, Lazzeroni LC, Hong DS \& Reiss AL. Aberrant parietal cortex developmental trajectories in girls with turner syndrome and related visual-spatial cognitive development: a preliminary study. American Journal of Medical Genetics Part B: Neuropsychiatric Genetics 2014165 531-540. (doi:10.1002/ ajmg.b.32256)

58 Green T, Bade Shrestha S, Chromik LC, Rutledge K, Pennington $\mathrm{BF}$, Hong DS \& Reiss AL. Elucidating X chromosome influences on attention deficit hyperactivity disorder and executive function. Journal of Psychiatric Research 201568 217-225. (doi:10.1016/j. jpsychires.2015.06.021)

59 Yeşilkaya E, Bereket A, Darendeliler F, Baş F, Poyrazoğlu Ş, Aydın BK, Darcan Ş, Dündar B, Büyükinan M, Kara C, et al. Turner syndrome and associated problems in Turkish children: a multicenter study. Journal of Clinical Research in Pediatric Endocrinology 20157 27-36.

60 Hong DS, Dunkin B \& Reiss AL. Psychosocial functioning and social cognitive processing in girls with turner syndrome. Journal of Developmental and Behavioral Pediatrics 201132 512-520. (doi:10.1097/DBP.0b013e3182255301)

61 El-Mansoury M, Barrenäs M-L, Bryman I, Hanson C \& LandinWilhelmsen K. Impaired body balance, fine motor function and

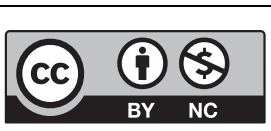

This work is licensed under a Creative Commons Attribution-NonCommercial 4.0 International License. 
hearing in women with Turner syndrome. Clinical Endocrinology 200971 273-278. (doi:10.1111/j.1365-2265.2008.03473.x) Wechsler D. Wechsler Intelligence Scale for Children, Fifth Edition. San Antonio, TX, USA: Pearson, 2014.

63 Kaufman AS \& Kaufman NL. Kaufman Assessment Battery for Children, Second Edition (KABC-2). San Antonio, TX, USA: Pearson, 2004.

64 Achenbach T. ASEBA School-Age Assessments. Burlington, VT, USA: ASEBA. (available at: http://www.aseba.org/schoolage.html)

65 Hong DS \& Reiss AL. Cognition and behavior in Turner syndrome: a brief review. Pediatric Endocrinology Reviews 20129710.

66 Rae C. Enlarged temporal lobes in turner syndrome: an X-chromosome effect? Cerebral Cortex 200414 156-164. (doi:10.1093/cercor/bhg114)

67 Ross JL, Roeltgen D, Feuillan P, Kushner H \& Cutler GB. Use of estrogen in young girls with Turner syndrome: effects on memory. Neurology 200054 164-170. (doi:10.1212/WNL.54.1.164)

68 Ross JL, Roeltgen D, Feuillan P, Kushner H \& Cutler GB. Effects of estrogen on nonverbal processing speed and motor function in girls with Turner's syndrome. Journal of Clinical Endocrinology and Metabolism 199883 3198-3204. (doi:10.1210/jc.83.9.3198)

69 Inozemtseva O, Matute E, Zarabozo D \& Ramírez-Dueñas L. Syntactic processing in Turner's syndrome. Journal of Child Neurology 200217 668-672. (doi:10.1177/088307380201700903)

70 Mazzocco MM, Thompson L, Sudhalter V, Belser RC, LesniakKarpiak K \& Ross JL. Language use in females with fragile X or Turner syndrome during brief initial social interactions. Journal of Developmental and Behavioral Pediatrics 200627 319-328. (doi:10.1097/00004703-200608000-00007)

71 Cristine T \& Elizabeth S. Exceptional lexical skills but executive language deficits in school starters and young adults with Turners syndrome: Implications for X chromosome effects on brain function. Brain and Language 120 345-359. (doi:10.1016/j. bandl.2011.12.001)

72 Kesler SR. Turner syndrome. Child and Adolescent Psychiatric Clinics of North America 200716 709-722. (doi:10.1016/j. chc.2007.02.004)

73 Skuse DH. X-linked genes and mental functioning. Human Molecular Genetics 200514 R27-R32. (doi:10.1093/hmg/ddi112)

74 Marco EJ \& Skuse DH. Autism-lessons from the X chromosome. Social Cognitive and Affective Neuroscience 20061 183-193. (doi:10.1093/scan/ns1028)

75 Russell HF. Increased prevalence of ADHD in Turner syndrome with no evidence of imprinting effects. Journal of Pediatrics and Psychology 200631 945-955. (doi:10.1093/jpepsy/jsj106)

76 Naess EE, Bahr D \& Gravholt CH. Health status in women with Turner syndrome: a questionnaire study on health status, education, work participation and aspects of sexual functioning. Clinical Endocrinology 201072 678-684. (doi:10.1111/j.13652265.2009.03715.x)

77 Zinn AR, Bondy CA, Phillip L, Van MS, Vladimir K \& Bakalov MD. Developmental endocrinology branch national institute of child health and human development national institutes of health. Ethnicity 200635 19-50.

78 Freriks K, Timmermans J, Beerendonk CCM, Verhaak CM, NeteaMaier RT, Otten BJ, Braat DD, Smeets DF, Kunst DH, Hermus $\mathrm{AR}$, et al. Standardized multidisciplinary evaluation yields significant previously undiagnosed morbidity in adult women with Turner syndrome. Journal of Clinical Endocrinology and Metabolism 201196 E1517-E1526. (doi:10.1210/jc.2011-0346)

79 Viner RM. Transition of care from paediatric to adult services: one part of improved health services for adolescents. Archives of Disease in Childhood 200893 160-163. (doi:10.1136/adc.2006.103721)

80 Gleeson H \& Turner G. Transition to adult services. Archives of Disease in Childhood: Education and Practice 201297 86-92. (doi:10.1136/archdischild-2011-300261)
81 Gleeson H. 'Part of the problem, part of the solution' - adult physicians' role in adolescent and young adult health. Clinical Medicine 201515 413-414. (doi:10.7861/clinmedicine.15-5-413)

82 Gawlik A, Kaczor B, Kaminska H, Zachurzok-Buczynska A, Gawlik T \& Malecka-Tendera E. Quality of medical follow-up of young women with Turner syndrome treated in one clinical center. Hormone Research in Paediatrics 201277 222-228. (doi:10.1159/000337780)

83 Stalla GK, Athanasoulia AP, Führer D, Frank-Herrmann P, Oppelt PG, Hauffa BP \& Dörr HG. Transition von jungen Frauen mit Ullrich-Turner-Syndrom in die Erwachsenenmedizin: Aktuelle Empfehlungen eines Expertenworkshops. Monatsschrift Kinderheilkunde 2013161 1180-1186. (doi:10.1007/s00112-0133016-2)

84 Devernay M, Ecosse E, Coste J \& Carel J-C. Determinants of medical care for young women with Turner syndrome. Journal of Clinical Endocrinology and Metabolism 200994 3408-3413. (doi:10.1210/jc.2009-0495)

85 White PH \& Ardoin S. Transitioning wisely: improving the connection from pediatric to adult health care. Arthritis and Rheumatology 201568 789-794. (doi:10.1002/art.39554)

86 Noom MJ, Deković M \& Meeus W. Conceptual analysis and measurement of adolescent autonomy. Journal of Youth and Adolescence 200130 577-595. (doi:10.1023/A:1010400721676)

87 Beacham BL \& Deatrick JA. Health care autonomy in children with chronic conditions. Nursing Clinics of North America 201348 305-317. (doi:10.1016/j.cnur.2013.01.010)

88 Hokken-Koelega A, van der Lely A-J, Hauffa B, Häusler G, Johannsson G, Maghnie M, Argente J, DeSchepper J, Gleeson $\mathrm{H}$, Gregory JW, et al. Bridging the gap: metabolic and endocrine care of patients during transition. Endocrine Connections 20165 R44-R54. (doi:10.1530/EC-16-0028)

89 Fair C, Cuttance J, Sharma N, Maslow G, Wiener L, Betz C, Porter J, McLaughlin S, Gilleland-Marchak J, Renwick A, et al. International and interdisciplinary identification of health care transition outcomes. JAMA Pediatrics 2016170 205-211. (doi:10.1001/jamapediatrics.2015.3168)

90 Müther S, Rodeck B, Wurst C \& Nolting H-D. Transition von Jugendlichen mit chronischen Erkrankungen in die Erwachsenenmedizin: Aktuelle Entwicklungen. Monatsschrift Kinderheilkunde 2014162 711-718. (doi:10.1007/s00112-0143103-z)

91 Nagra A, McGinnity PM, Davis N \& Salmon AP. Implementing transition: ready steady go. Archives of Disease in Childhood: Education and Practice Edition 2015100 313-320. (doi:10.1136/ archdischild-2014-307423)

92 Huang JS, Terrones L, Tompane T, Dillon L, Pian M, Gottschalk M, Norman GJ \& Kay Bartholomew L. Preparing adolescents with chronic disease for transition to adult care: a technology program. Pediatrics 2014133 e1639-e1646. (doi:10.1542/ peds.2013-2830)

93 National Alliance to Advance Adolescent Health. Got Transition. Washington, DC, USA: National Alliance to Advance Adolescent Health, 2014. (available at: http://www.gottransition.org/ providers/index.cfm)

94 Müther S \& Findorff J. Berliner transitionsprogramm: sektorenübergreifendes strukturprogramm für die transition jugendlicher mit chronischer erkrankung. Pädiatrie and Pädologie 201651 25-29. (doi:10.1007/s00608-016-0348-x)

95 Thyen U, Bomba F, Menrath I, Schmidt J, Szczepanski R, Ernst G \& Silke Schmidt. Patientenschulungen in der transition: empowerment für Jugendliche mit chronischen Erkrankungen. Pädiatrie and Pädologie 201651 30-35. (doi:10.1007/s00608-0160347-y)

96 Downing J, Gleeson HK, Clayton PE, Davis JRE, Wales JK \& Callery P. Transition in endocrinology: the challenge of 
maintaining continuity. Clinical Endocrinology 201378 29-35. (doi:10.1111/j.1365-2265.2012.04473.x)

97 Gleeson H, Davis J, Jones J, O'Shea E \& Clayton PE. The challenge of delivering endocrine care and successful transition to adult services in adolescents with congenital adrenal hyperplasia: experience in a single centre over 18 years. Clinical Endocrinology 201378 23-28. (doi:10.1111/cen.12053)

98 Watson R, Parr JR, Joyce C, May C \& Le Couteur AS. Models of transitional care for young people with complex health needs: a scoping review: models of transitional care. Child: Care, Health and Development 201137 780-791. (doi:10.1111/j.13652214.2011.01293.x)

99 Prior M, McManus M, White P \& Davidson L. Measuring the 'Triple Aim' in transition care: a systematic review. Pediatrics 2014 134 e1648-e1661. (doi:10.1542/peds.2014-1704)

100 Moynihan M, Saewyc E, Whitehouse S, Paone M \& McPherson G. Assessing readiness for transition from paediatric to adult health care: revision and psychometric evaluation of the Am I ON TRAC for Adult Care questionnaire. Journal of Advanced Nursing 201571 1324-1335. (doi:10.1111/jan.12617)

101 Sawicki GS, Lukens-Bull K, Yin X, Demars N, Huang I-C, Livingood W, Reiss J \& Wood D. Measuring the transition readiness of youth with special healthcare needs: validation of the TRAQ - transition readiness assessment questionnaire. Journal of Pediatrics and Psychology 201136 160-171. (doi:10.1093/jpepsy/jsp128)

102 Nguyen T, Henderson D, Stewart D, Hlyva O, Punthakee Z \& Gorter JW. You never transition alone! Exploring the experiences of youth with chronic health conditions, parents and healthcare providers on self-management: self-management for youth with chronic health conditions. Child: Care, Health and Development $\mathbf{4 2}$ 464-472. (doi:10.1111/cch.12334)

103 Wood DL, Sawicki GS, Miller MD, Smotherman C, Lukens-Bull K, Livingood WC, Ferris $\mathrm{M} \&$ Kraemer DF. The transition readiness assessment questionnaire (TRAQ): its factor structure, reliability, and validity. Academic Pediatrics 201414 415-422. (doi:10.1016/j. acap.2014.03.008)

104 Reindollar R. Turner syndrome: contemporary thoughts and reproductive issues. Seminars in Reproductive Medicine 201129 342-352. (doi:10.1055/s-0031-1280919)

105 Grynberg M, Bidet M, Benard J, Poulain M, Sonigo C, CédrinDurnerin I \& Polak M. Fertility preservation in Turner syndrome. Fertility and Sterility 2016105 13-19. (doi:10.1016/j. fertnstert.2015.11.042)

106 Bernard V, Donadille B, Zenaty D, Courtillot C, Salenave S, Brac de la Perrière A, Albarel F, Fèvre A, Kerlan V, Brue T, et al. Spontaneous fertility and pregnancy outcomes amongst 480 women with Turner syndrome. Human Reproduction 201631 782-788. (doi:10.1093/humrep/dew012)

107 Carel J-C, Ecosse E, Bastie-Sigeac I, Cabrol S, Tauber M, Léger J, Nicolino M, Brauner R, Chaussain JL \& Coste J. Quality of life determinants in young women with Turner's syndrome after growth hormone treatment: results of the StaTur populationbased cohort study. Journal of Clinical Endocrinology and Metabolism 200590 1992-1997. (doi:10.1210/jc.2004-1395)

108 Bannink EMN, Raat H, Mulder PGH \& de Muinck Keizer-Schrama SMPF. Quality of life after growth hormone therapy and induced puberty in women with turner syndrome. Journal of Pediatrics 2006148 95-101. (doi:10.1016/j.jpeds.2005.08.043)
109 Taback SP \& Van Vliet G. Health-related quality of life of young adults with Turner syndrome following a long-term randomized controlled trial of recombinant human growth hormone. BMC Pediatrics 201111 1. (doi:10.1186/1471-2431-11-1)

110 Roelofs RL, Wingbermühle E, Freriks K, Verhaak CM, Kessels RPC \& Egger JIM. Alexithymia, emotion perception, and social assertiveness in adult women with Noonan and Turner syndromes. American Journal of Medical Genetics Part A 2015167 768-776. (doi:10.1002/ajmg.a.37006)

111 van Pareren YK, Duivenvoorden HJ, Slijper FME, Koot HM, Drop SLS \& de Muinck Keizer-Schrama SMPF. Psychosocial functioning after discontinuation of long-term growth hormone treatment in girls with turner syndrome. Hormone Research in Paediatrics 2005 63 238-244. (doi:10.1159/000085841)

112 Sheaffer AT, Lange E \& Bondy CA. Sexual function in women with turner syndrome. Journal of Women's Health 200817 27-33. (doi:10.1089/jwh.2007.0488)

113 Boman UW, Bryman I \& Möller A. Psychological well-being in women with Turner syndrome: somatic and social correlates. Journal of Psychosomatic Obstetrics and Gynecology 200425 211-219. (doi:10.1080/01674820400017855)

114 Stochholm K, Hjerrild B, Mortensen KH, Juul S, Frydenberg M \& Gravholt CH. Socioeconomic parameters and mortality in Turner syndrome. European Journal of Endocrinology 2012166 1013-1019. (doi:10.1530/EJE-11-1066)

115 Fjermestad KW, Naess EE, Bahr D \& Gravholt CH. A 6-year follow-up survey of health status in middle-aged women with Turner syndrome. Clinical Endocrinology 201685 423-429. (doi:10.1111/cen.13068)

116 Gould HN, Bakalov VK, Tankersley C \& Bondy CA. High levels of education and employment among women with turner syndrome. Journal of Women's Health 201322 230-235. (doi:10.1089/jwh.2012.3931)

117 Folsom LJ \& Fuqua JS. Reproductive issues in women with turner syndrome. Endocrinology and Metabolism Clinics of North America 201544 723-737. (doi:10.1016/j.ecl.2015.07.004)

118 Oktay K, Bedoschi G, Berkowitz K, Bronson R, Kashani B, McGovern P, Pal L, Quinn G \& Rubin K. Fertility preservation in women with turner syndrome: a comprehensive review and practical guidelines. Journal of Pediatric and Adolescent Gynecology 201629 409-416. (doi:10.1016/j.jpag.2015.10.011)

119 Wechsler D. Wechsler Adult Intelligence Scale, Fourth Edition (WAIS-IV). San Antonio, TX, USA: Pearson, 2008.

120 Weitzman C \& Wegner L. The section on developmental and behavioral pediatrics, committee on psychosocial aspects of child and family health, council on early childhood, and society for developmental and behavioral pediatrics. Promoting optimal development: screening for behavioral and emotional problems. Pediatrics 2015135 384-395. (doi:10.1542/ peds.2014-3716)

121 Council on Children with Disabilities, Section on Developmental Behavioral Pediatrics, Bright Futures Steering Committee \& Medical Home Initiatives for Children with Special Needs Project Advisory Committee. Identifying infants and young children with developmental disorders in the medical home: an algorithm for developmental surveillance and screening. Pediatrics 2006118 405-420. (doi:10.1542/ peds.2006-1231)

Received in final form 8 March 2017

Accepted 22 March 2017

Accepted Preprint published online 23 March 2017 http://www.endocrineconnections.org DOI: 10.1530/EC-17-0036 (c) 2017 The authors Published by Bioscientifica Ltd

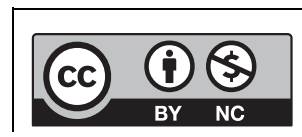

This work is licensed under a Creative Commons Attribution-NonCommercial 4.0 International License. 